\title{
ANÁLISE DO ÍNDICE DE ANOMALIA DE CHUVA (IAC) APLICADO À BACIA HIDROGRÁFICA DO RIO URUSSANGA/SC
}

\author{
ANALYSIS OF THE RAIN ANOMALY INDEX (RAI) APPLIED TO \\ THE HYDROGRAPHIC BOWL OF URUSSANGA RIVER
}

\section{Marlon Domingos Cury Engenheiro Civil e Ambiental, Mestre em Ciências Ambientais/UNESC. E-mail: marlon.dcury@gmail.com \\ Daniel Pazini Pezente \\ Engenheiro Agrônomo, Mestre em Ciências Ambientais/UNESC. E-mail: pezented@hotmail.com \\ Thaise Sutil \\ Engenheira de Bioprocessos e Biotecnologia, Mestre em Ciências Ambientais/UNESC. E-mail: thaise.sutil@gmail.com \\ Juliana Debiasi Menegasso \\ Mestranda em Ciências Ambientais/UNESC. E-mail: julianaorleans@gmail.com}

\section{RESUMO}

Os eventos climáticos extremos assumem importância no cotidiano das sociedades. Dessa forma, conhecer a quantidade, intensidade e a distribuição espacial da precipitação pluvial contribui para a gestão e o planejamento territorial da área estudada. Uma das formas de se estudar a precipitação pluvial de determinada região é através de Índices de Anomalia de Chuva (IAC). O presente trabalho tem como objetivo analisar a variabilidade das precipitações anuais em três municípios inseridos na Bacia Hidrográfica do Rio Urussanga do Estado de Santa Catarina, evidenciando os anos de seca e chuva. Içara, Jaguaruna e Urussanga foram os municípios selecionados. Os dados foram obtidos pela ANA, para um período de 37 anos. Os cálculos do IAC foram realizados com base nas médias anuais e médias dos 10 anos de máximas e mínimas precipitações. Urussanga foi o município mais chuvoso, apresentou 22 desvios negativos e 15 desvios positivos. O município de Içara apresentou 25 desvios negativos e 12 desvios positivos, assim como o município de Içara, onde houve 25 desvios negativos e 12 positivos em Jaguaruna. Com o emprego do IAC, foi possível visualizar o grau de variação da precipitação da região estudada.

Palavras-chave: Hidrologia. Precipitação. Climatologia.

\begin{abstract}
The extreme climatic events are significant in the daily life of the societies, knowing the quantity, intensity and spatial distribution of rainfall contribute to the management and territorial planning of the studied area. One of the ways to study the rainfall of a given region is through Rainfall Anomaly Index (IAC). The present study had the objective of analyzing the IAC in three municipalities Inserted in the Urussanga River Basin of the State of Santa Catarina, evidencing the years of drought and rain. Içara, Jaguaruna and Urussanga were the municipalities selected. The data were obtained by the ANA, for a period of 37 years. IAC calculations were performed based on monthly averages and averages of 10 years of maximum and minimum rainfall. Urussanga was the rainiest presented 22 negative deviations and 15 positive deviations. The municipality of Içara presented 25 negative deviations and 12 positive deviations. As well as the municipality of Içara, there were 25 negative and 12 positive deviations. With the use of IAC, it was possible to visualize the degree of variation of the rain around the normal climatological, presenting as a good climatic indicator to evaluate the rainfall variability.
\end{abstract}

Keywords: Hidrology. Rainfall. Climatology. 


\section{INTRODUÇÃO}

O estudo do impacto das mudanças climáticas sobre os recursos hídricos é um fato de grande relevância socioambiental e, em situação extrema, pode comprometer a sustentabilidade da sociedade e da conservação da biodiversidade. As mudanças climáticas globais influenciam diretamente no ciclo hidrológico e na quantidade e qualidade da água, sendo que essas alterações podem promover inúmeras mudanças na disponibilidade de água, na saúde da população humana, além de alterarem a composição de ecossistemas terrestres e aquáticos (MARENGO, DIAS; 2006; LIMA et al., 2016).

De modo geral e com alterações diversas em continentes e regiões, três problemas fundamentais devem ser estudados para promover soluções:

a) extremos hidrológicos que ocorrerão em diferentes continentes e regiões que afetarão populações humanas em razão de desastres (enchentes, deslizamentos, transbordamentos nas várzeas) ou secas intensas (aumento na semiaridez e aridez)

b) contaminação - os estudos desenvolvidos em muitas regiões apontam para um aumento acentuado de contaminação agravado por salinização e descontrole nos usos do solo; e

c) água e economias regionais e nacionais - intensificando os conflitos referentes aos usos múltiplos da água. Esses extremos hidrológicos e o aumento da contaminação deverão atuar nas economias regionais, tendo como consequência profundas alterações na economia dependente da disponibilidade e demanda dos recursos hídricos (TUNDISI, 2008).

Na década de 1970, a ocorrência de secas extremas como consequência de alterações climáticas, em várias regiões da Terra, evidenciou a vulnerabilidade do ser humano frente a esse risco climático, demonstrando a necessidade de uma melhor compreensão, melhor previsão de sua ocorrência e o correto uso de medidas mitigatórias. Nos últimos anos, o número de eventos e o de pessoas afetadas pelas inundações aumentou significativamente, acompanhando a tendência relacionada a todos os tipos de desastres naturais. Isso ocorre por causa da falta de controle do espaço urbano, produzindo efeito direto sobre a infraestrutura hídrica: abastecimento, esgotamento sanitário, drenagem urbana, inundações ribeirinhas e resíduos sólidos (TUCCI, 2010; NORONHA et al., 2016).

A precipitação influencia diretamente nas atividades antrópicas, visto que, chuvas em excesso e períodos longos de estiagem e seca trazem conseqüências negativas tanto para a economia quanto para o setor socioambiental. 
Por se tratar de um elemento meteorológico que apresenta uma grande variabilidade espaço-temporal, influenciado diretamente pela localização geográfica da bacia hidrográfica, pelo relevo e também pelas demais variáveis meteorológicas, destaca-se a importância de estudos que possam fundamentar as tomadas de decisões, especialmente no planejamento territorial de um município (DINIZ, 2013).

O monitoramento da precipitação pluviométrica pode ser realizado com a utilização de índices de verificação climática, os quais caracterizam os períodos secos e chuvosos, para entender o comportamento climatológico de uma região e a severidade desses fenômenos e seus impactos (COSTA, SILVA, 2017).

Alguns estudos foram realizados na Bacia Hidrográfica do Rio Urussanga, a fim de avaliar as modificações climáticas ocorridas, como a de Denski e Back (2015), que, ao avaliar a tendência climatológica nos elementos meteorológicos e na evapotranspiração de referência de Urussanga - SC, observaram uma tendência estatisticamente significativa para o aumento da temperatura média anual e uma tendência significativa de aumento da temperatura média anual de $0,0174{ }^{\circ} \mathrm{C}$.ano- ${ }^{1}$ ou $0,174{ }^{\circ} \mathrm{C}$ por década. Ao aplicar a análise estatística para a identificação de tendências climáticas na Bacia Hidrográfica do Rio Urussanga Back (2001), observou-se uma tendência significativa no aumento da precipitação pluvial total anual, e da precipitação pluvial total no quarto trimestre.

Ao pesquisar a variabilidade de índices de chuva nos estados de Santa Catarina e Rio Grande do Sul, Minuzzi e Lopez (2014) observaram um aumento na quantidade de chuva, no número de dias chuvosos e, de forma mais discreta, no número e na intensidade dos eventos extremos de chuva, sobretudo na primavera e no outono desde meados do século XX.

Uma das formas de obter a caracterização da variabilidade espaço-temporal em determinada região de estudo é a utilização do Índice de Anomalia de Chuva (IAC), que ajuda a monitorar anos de seca e chuva excessiva, permitindo a realização de comparações do regime pluviométrico a partir de uma série de dados históricos de chuva. Outra vantagem do IAC é que ele necessita apenas de dados de precipitação e é de fácil estimativa (ARAÚJO et al., 2007; ARAÚJO et al., 2009; MARCUZZO et al., 2011; SANCHES et al., 2014).

De acordo com Freitas (2005), o Índice de Anomalia de Chuva, além de ser de fácil aplicabilidade, é também bastante preciso comparado a outros índices. Desenvolvido por Rooy (1965), o Rainfall Anomaly Index (RAI) ou Índice de Anomalia de Chuva (IAC) é utilizado para classificar as severidades positivas e negativas nas anomalias de precipitações (FERNANDES et al., 2009; DA SILVA, 2007). 
Dada a importância das alterações das mudanças climáticas e da necessidade de melhor conhecer e interpretar as escalas temporais da variabilidade pluviométrica, este trabalho se propõe a investigar, através do Índice de Anomalia de Chuva (IAC) proposto por Rooy (1965), as séries temporais dos municípios de Içara, Jaguaruna e Urussanga inseridas na Bacia Hidrográfica do Rio Urussanga.

\section{MATERIAIS E MÉTODOS}

\section{ÁREA DE ESTUDO}

Segundo Ladwig et al. (2017), a Bacia Hidrográfica do Rio Urussanga possui uma área territorial de $679,687631 \mathrm{~km}^{2}$, correspondendo a 67968,7631 ha, localizada entre as coordenadas geográficas $28^{\circ} 25^{\prime} 56^{\prime \prime}$ e $28^{\circ} 48^{\prime} 42^{\prime \prime}$ de latitude sul e $49^{\circ} 23^{\prime} 56^{\prime \prime}$ e $49^{\circ} 01^{\prime} 15^{\prime \prime}$ de longitude oeste do meridiano de Greenwich, situada no estado de Santa Catarina, como representada na Figura 1. Possui área nos municípios de Balneário Rincão, Cocal do Sul, Criciúma, Içara, Jaguaruna, Morro da Fumaça, Pedras Grandes, Sangão, Treze de Maio e Urussanga.

Figura 1 - Mapa de localização da área de estudo
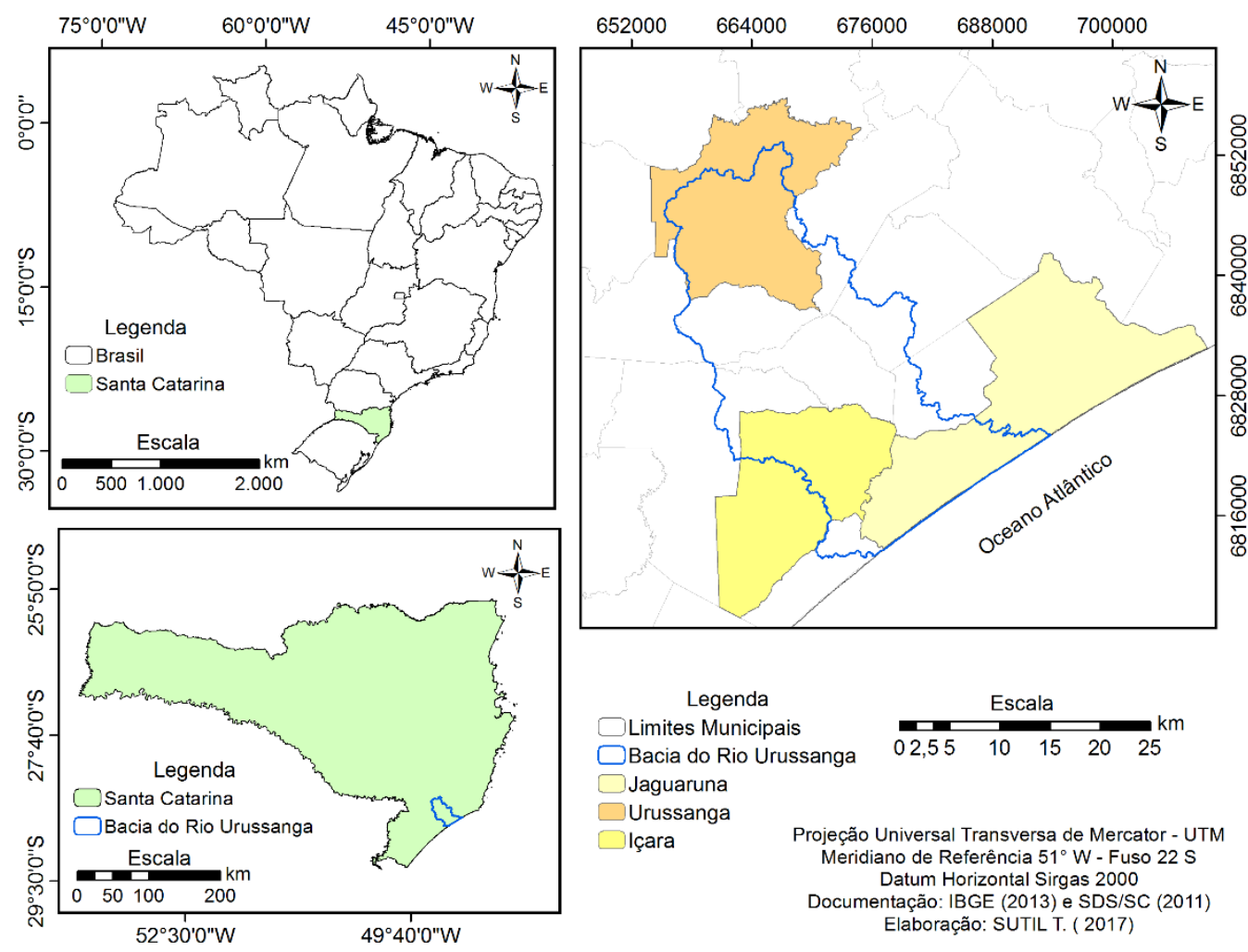

Fonte: Elaborada pelos autores. 


\section{Dados}

Os dados pluviométricos diários utilizados neste estudo foram obtidos na rede de postos da Agência Nacional de Águas (ANA, 2016), através da plataforma hidroweb (Disponível em: <http://hidroweb.ana.gov.br>), sendo selecionadas para esta pesquisa as informações dos postos de Içara, Jaguaruna e Urussanga inseridos na Bacia Hidrográfica do Rio Urussanga. Os dados mensais de precipitação foram agrupados em totais anuais para a obtenção dos IAC da série.

Como critério de escolha dos municípios, optou-se por aqueles que tivessem uma série histórica superior a 20 anos, de no mínimo dois períodos consecutivos de cinco anos. Para a tabulação, realização dos cálculos das séries históricas selecionadas e a elaboração dos gráficos representativos, foi utilizada uma planilha eletrônica (Software Microsoft Office Excel), sendo obtidas as médias mensais e anuais das séries.

Para a determinação do índice de anomalia de chuva (IAC), utilizou-se a metodologia sugerida por Rooy (1965) e adaptada por Freitas (2005), a qual utilizada duas equações: uma para as anomalias positivas (a) e outra para as anomalias negativas (b).
IAC: $\quad 3:\left[\frac{(\mathrm{N}-\overline{\mathrm{N}})}{(\overline{\mathrm{M}-\mathrm{N}})}\right]$
IAC: $-3 *\left[\frac{(\mathrm{N}-\overline{\mathrm{N}})}{(\overline{\mathrm{x}-\mathrm{N}})}\right]$

Em que: $\mathrm{N}$ - precipitação mensal atual $\left(\mathrm{mm} \cdot \mathrm{mês}^{-1}\right), \overline{\mathrm{N}}$ - precipitação média mensal da série histórica (mm.mês $\left.{ }^{-1}\right), \bar{M}-$ média das dez maiores precipitações mensal da série histórica (mm.mês-1) e · - média das dez menores precipitações mensal da série histórica (mm.mês $\left.{ }^{-1}\right)$.

Para a realização da disposição dos municípios em termos de IAC, foi utilizada a metodologia proposta por Araújo et al. (2009) para os anos secos e úmidos. A classificação é feita de acordo com os valores registrados para o IAC, como mostra a Tabela 1.

Tabela 1 - Classes do Índice de Anomalia de Chuva

\begin{tabular}{ccl}
\hline Índice & $\begin{array}{c}\text { Faixa de } \\
\text { IAC }\end{array}$ & \multicolumn{1}{c}{ Classe de Intensidade } \\
\hline & $>4$ & Extremamente Chuvoso \\
& 2 a 4 & Muito Chuvoso \\
Índice de Anomalia de Chuva & 0 a 2 & Chuvoso \\
(IAC) & 0 a -2 & Seco \\
& -2 a -4 & Muito Seco
\end{tabular}




\section{$<-4 \quad$ Extremamente Seco}

Fonte: Araújo et al., 2009.

\section{RESULTADOS E DISCUSSÃO}

Com a utilização do IAC, possibilitou-se identificar padrões ou mudanças no comportamento das precipitações, o que permitiu determinar a severidade dos ciclos secos e chuvosos na área de estudo (GONÇALVES; BACK; 2017). Os Gráficos 1, 2 e 3 apresentam o comportamento das médias mensais para a precipitação pluvial, permitindo a visualização das épocas chuvosas e secas para os municípios de Içara, Jaguaruna e Urussanga, respectivamente.

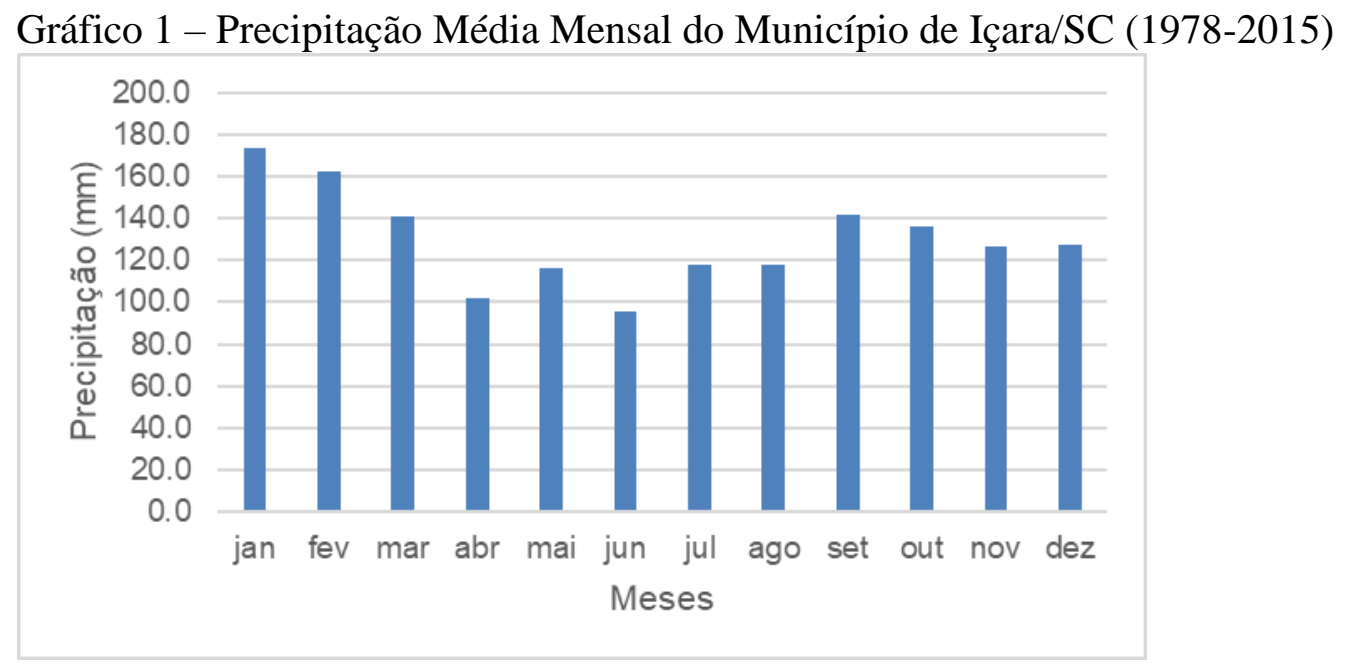

Fonte: Elaborado pelos autores.

Gráfico 2 - Precipitação Média Mensal do Município de Jaguaruna/SC (19782015)

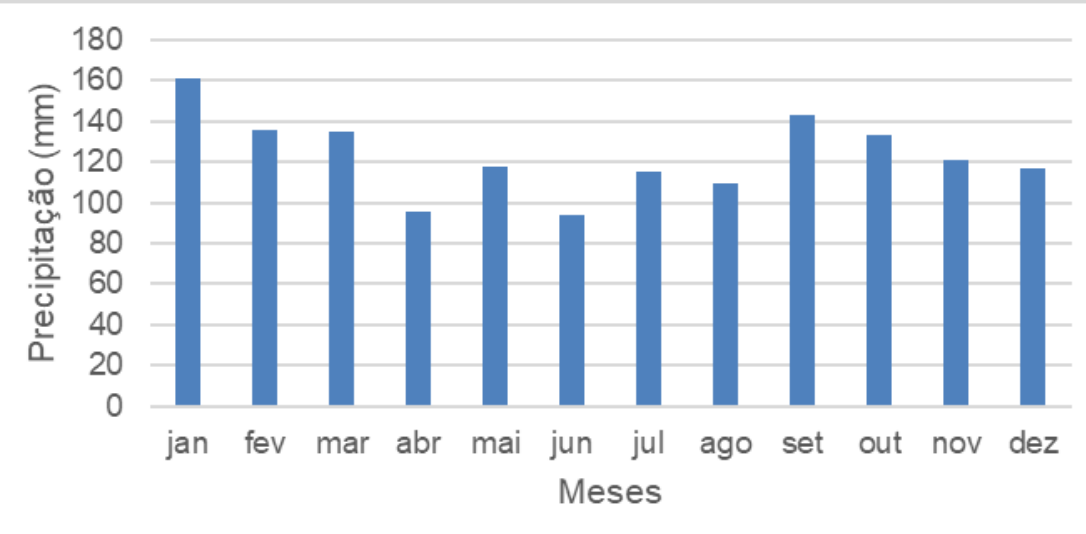

Fonte: Elaborado pelos autores. 
Gráfico 3 - Precipitação Média Mensal do Município de Urussanga/SC (19782015)

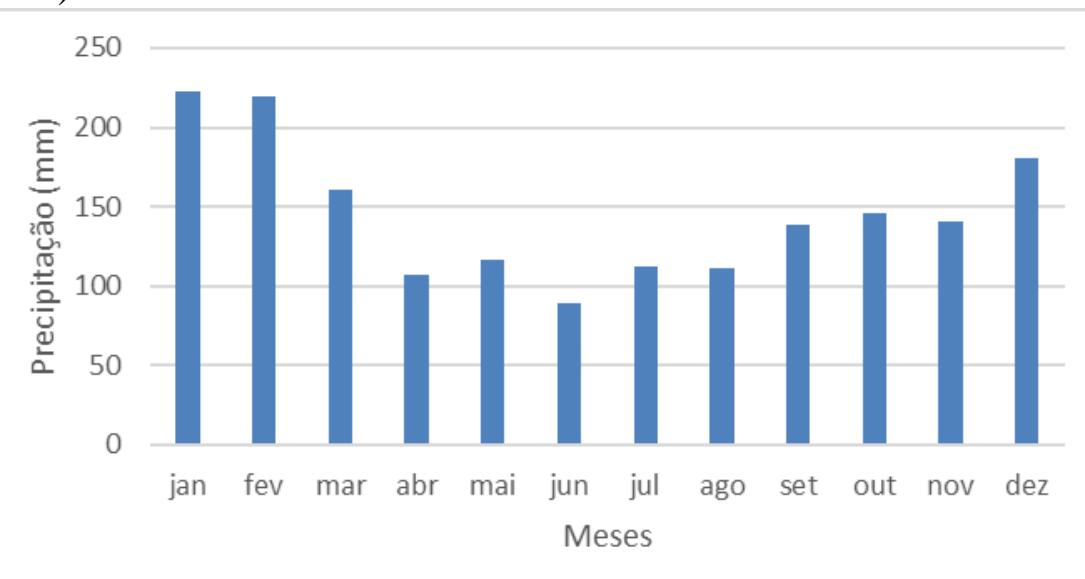

Fonte: Elaborado pelos autores.

O município de Içara, localizado no litoral sul do estado de Santa Catarina, apresentou uma precipitação média anual de $1.562,9 \mathrm{~mm}$, com os meses mais chuvosos entre janeiro $(174,0 \mathrm{~mm})$, fevereiro $(162,5 \mathrm{~mm})$ e março $(141,0 \mathrm{~mm})$. O município mais chuvoso entre os três analisados é Urussanga, com uma precipitação média anual de 1.745,4 mm, concentrando os maiores valores entre os meses de dezembro $(222,7 \mathrm{~mm})$, janeiro $(219,7 \mathrm{~mm})$ e fevereiro $(180,7 \mathrm{~mm})$. Os meses mais chuvosos do município de Jaguaruna foram os de janeiro (160,9 $\mathrm{mm})$, fevereiro $(135,5 \mathrm{~mm})$ e setembro $(143,2 \mathrm{~mm})$, com uma precipitação média anual de $1.449,5 \mathrm{~mm}$.

Valores positivos de IAC significam que determinado ano foi chuvoso, podendo ser classificado na classe de intensidade como chuvoso, muito chuvoso ou extremamente chuvoso, e os valores negativos representam os anos secos, com classificação de seco, muito seco ou extremamente seco (ARAÚJO et al., 2009). Para o município de Içara entre o período de 1978 a 2015, houve 25 desvios negativos e uma predominância de anos classificados como secos (30\%), seguido por anos muito secos (26,5\%) e 12 desvios positivos, com predominância de anos chuvosos $(23,7 \%)$ e muito chuvosos $(12,1 \%)$. Os casos extremos de chuvas e secas obtiveram uma porcentagem de $5,3 \%$ e $2,4 \%$, respectivamente. O IAC do município variou entre -2,61 e 2,60, conforme Gráfico 4. É possível observar um período de seca entre os anos de 1978 e 1982, e um grande período de seca de 1991 a 1999. Os períodos chuvosos ficaram concentrados entre os anos de 2000 a 2003 e 2009 a 2011. 
Gráfico 4 - Índice de Anomalia de Chuva do Município de Içara/SC

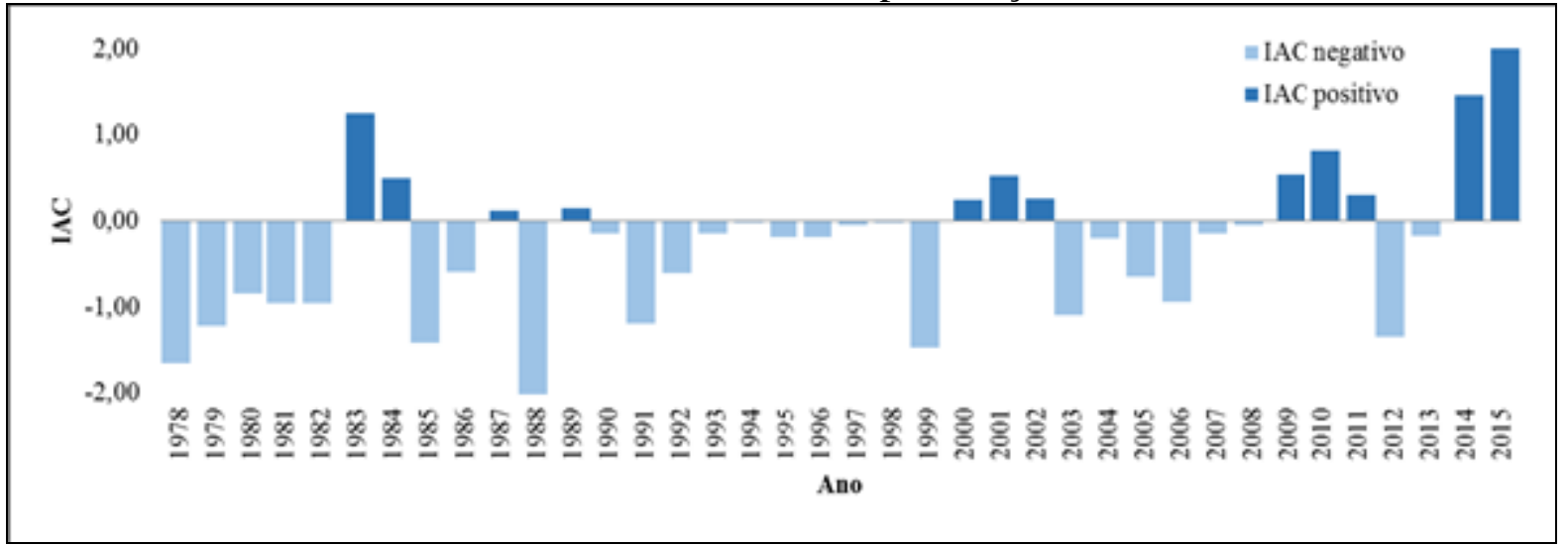

Fonte: Elaborado pelos autores.

O município de Jaguaruna entre o período de 1978 a 2015, assim como o município de Içara, apresentou 25 desvios negativos com uma predominância de anos classificados como secos $(29,4 \%)$, seguido por anos muito secos $(25,4 \%)$ e 12 desvios positivos, com predominância de anos chuvosos $(24,1 \%)$ e muito chuvosos $(10.7 \%)$. Os casos extremos de chuvas e secas obtiveram uma porcentagem de $5,9 \%$ e $4,4 \%$, respectivamente. O IAC do município variou entre -1,76 e 2,42, conforme Gráfico 5. É possível observar um período de seca dos anos de 1988 a 1994, 2003 a 2008 e 2011 a 2014. Os períodos chuvosos ficaram concentrados entre os anos de 1995 e 1998 e 2009 e 2010.

Gráfico 5 - Índice de Anomalia de Chuva do Município e Jaguaruna/SC

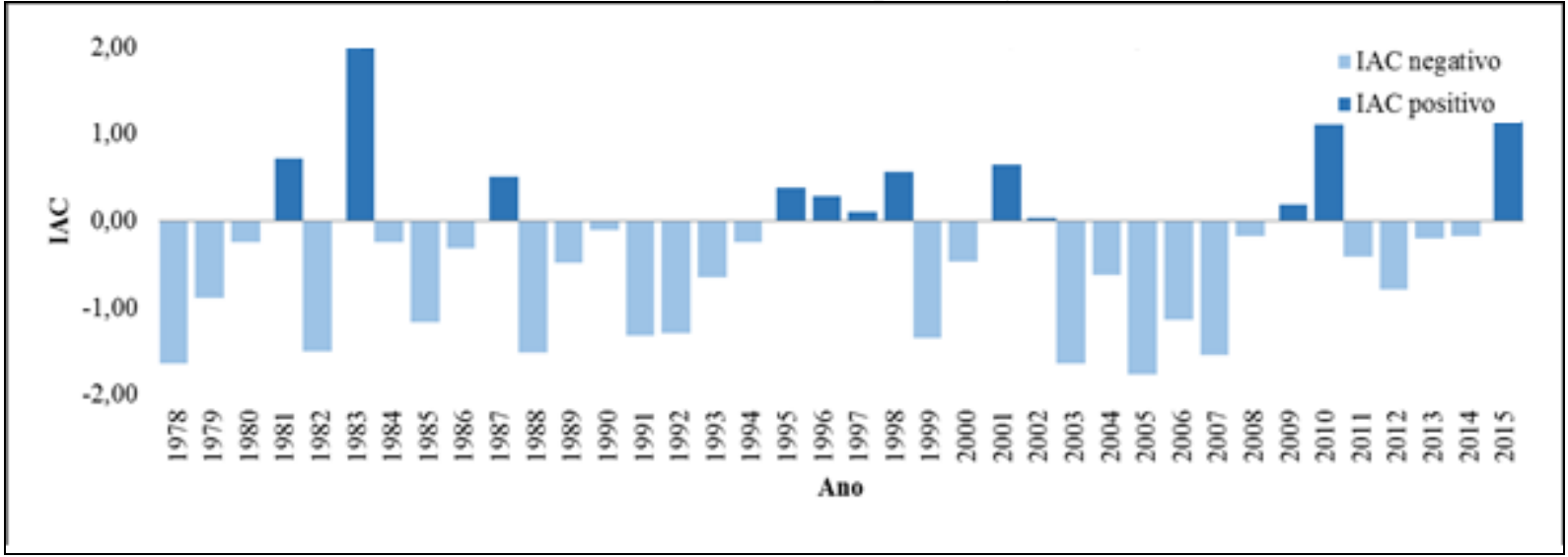

Fonte: Elaborado pelos autores.

Já o município de Urussanga, entre o período de 1978 a 2015, apresentou 22 desvios negativos com uma predominância de anos classificados como secos $(29,8 \%)$, seguido por anos muito secos $(25,7 \%)$ e 15 desvios positivos, com predominância de anos chuvosos 
$(25,7 \%)$ e muito chuvosos $(12,3 \%)$. Os casos extremos de chuvas e secas obtiveram uma porcentagem de $5,3 \%$ e $2,4 \%$, respectivamente. O IAC do município variou entre -1,55 e 2,28, conforme Gráfico 6. É possível observar um período de seca entre os anos de 1978 a 1992 e 2003 a 2008. Os períodos chuvosos ficaram concentrados entre os anos de 2008 a 2011. Vale salientar que o ano de 1983 obteve os maiores índices positivos nos municípios de Jaguaruna e Urussanga, sendo o segundo maior ano do município de Içara.

Gráfico 6 - Índice de Anomalia de Chuva do Município de Urussanga/SC

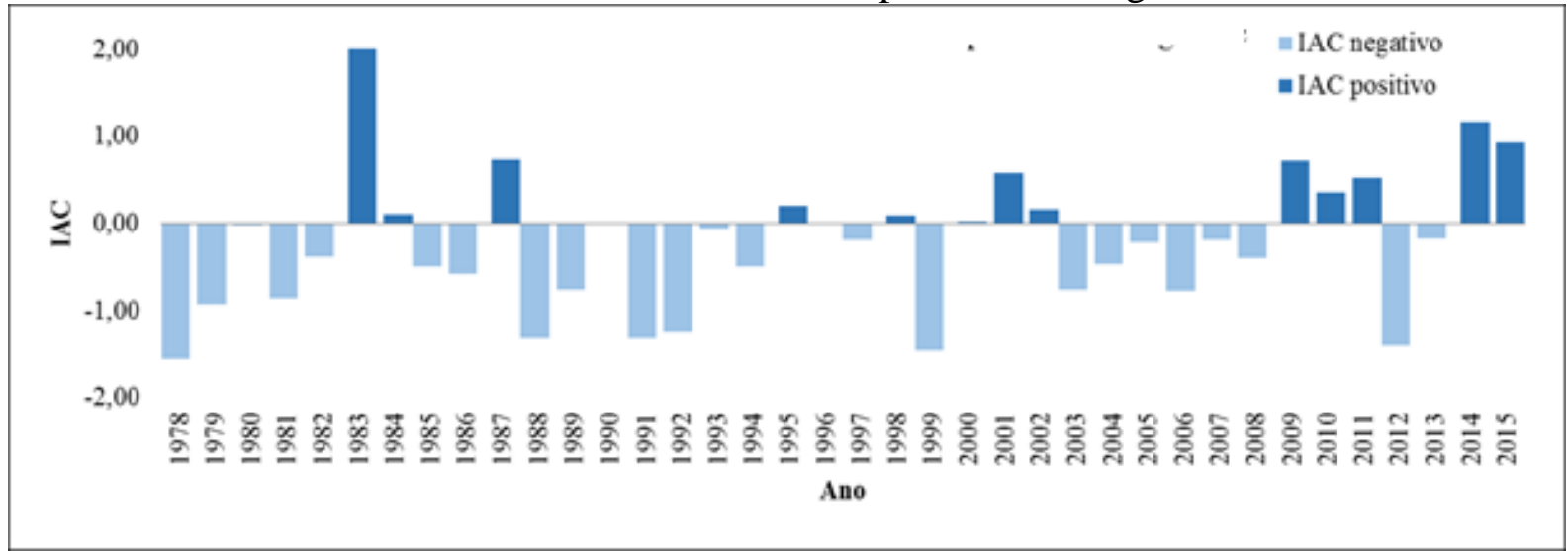

Fonte: Elaborado pelos autores.

\section{CONSIDERAÇÕES FINAIS}

Com a utilização do IAC, foi possível visualizar o grau de variação da precipitação em torno das médias mensais, apresentando-se como um bom indicador climático para se avaliar a variabilidade pluviométrica.

O IAC demonstrou-se uma ferramenta de uso e interpretação relativamente simples e de resultado bastante eficiente que pode ser utilizado para a gestão e planejamento de bacias hidrográficas e, consequentemente, evitar problemas relacionados à escassez ou excesso de água.

\section{REFERÊNCIAS}

AGÊNCIA NACIONAL DE ÁGUAS. ANA Sistemas de Informações Hidrológicas. Disponível em: <http://hidroweb.ana.gov.br>. Acesso em 20 ago. 2017.

ARAUJO, L. E. de; SILVA, D. F da; MORAES NETO, J. M. de; SOUSA, F. de A. S. de. Analise da variabilidade espaço-temporal da precipitação na bacia do rio Paraíba usando IAC. Revista de Geografia, Recife, v. 24, n. 1, p. 47-59. jan/abr. 2007.

ARAÚJO, L. E. et al. Análise climática da bacia do rio Paraíba - Índice de Anomalia de Chuva (IAC). Revista de Engenharia Ambiental, v. 6, n. 3, p. 508-523, 2009.

BACK, A. J. Aplicação de análise estatística para identificação de tendências climáticas. Pesq. Agropecuária Brasileira, Brasília, v. 36, n. 5, p. 717-726, 2001. 
COSTA, J. A.; DA SILVA, D. F. Distribuição espaço-temporal do Índice de anomalia de chuva para o Estado do Ceará. Revista Brasileira de Geografia Física, v. 10, n. 4, p. 1002-1013, 2017.

DA SILVA, D. F.; ARAÚJO, L. E.; KAYANO, M. T.; SOUSA, F. de A. S. Avaliação dos impactos da variabilidade climática na distribuição pluviométrica da Bacia do Rio Mundaú através do IAC. In: Simpósio Brasileiro de Desastres naturais e Tecnológicos, 2, 2007, Santos: [S.n.], 2007. v. 72.

DENSKI, A. P. N.; BACK, Á. J. Tendência climatológica nos elementos meteorológicos e na evapotranspiração de referência de Urussanga - SC. Revista Brasileira de Climatologia, Curitiba, v. 17, p. 262-274, 2015.

DINIZ, J. M. T., Variabilidade da precipitação e do número de dias com chuvas de duas cidades distintas da Paraíba, Holos, v. 3, p. 171-180, 2013.

FERNANDES, D.S.; HEINEMANN, A.B.; PAZ, R.L.F.; AMORIM, A. O. Desempenho de índices quantitativos de seca na estimativa da produtividade de arroz de terras altas. Pesquisa Agropecuária Brasileira, v. 45, p. 771-779, 2010.

FREITAS, M. A. S. Um Sistema de suporte à decisão para o monitoramento de secas meteorológicas em regiões semi-áridas. Revista Tecnologia, Fortaleza, v. suplem, p. 84-95, 2005.

GONÇALVES, Fabiane Nunes; BACK, Álvaro José. Análise do índice de anomalia de chuva (IAC) para o município de Palmitos, no extremo oeste do estado de Santa Catarina. In: LADWIG, Nilzo Ivo; SCHWALM, Hugo (Orgs.). Planejamento e gestão territorial: gestão integrada do território. Criciúma: UNESC, 2017. p. 252-260.

LIMA, Julião Soares de Souza; SILVA, S. DE A.; BERNARDES, P. M.; FONSECA, A. S.; PEREIRA, J. M. S.. Variabilidade espacial dos percentis 75 da precipitação pluvial mensal no estado do espírito santo. Revista Engenharia Na Agricultura, v. 24, p. 393-405, 2016.

MARCUZZO, F. F. N.; MELO, D. C. R.; ROCHA, H. M. Distribuição espaço-temporal e sazonalidade das chuvas no Estado do Mato Grosso. Revista Brasileira de Recursos Hídricos, v. 16, n. 4, p. 157-167, 2011.

MARENGO, J. A.; DIAS, P. S. Mudanças climáticas globais e seus impactos nos recursos hídricos. In: REBOUÇAS, A. C.; BRAGA, B.; TUNDISI, J. G. (Eds.). Águas doces no Brasil: capital ecológico, uso e conservação. 3. ed. São Paulo: Instituto de Estudos Avançados da USP, Academia Brasileira de Ciências, 2006. p. 63-109.

MINUZZI, R. B. and LOPEZ, R. Z. Variabilidade de índices de chuva nos estados de Santa Catarina e Rio Grande do Sul. Bioscience Journal, v. 30 n. 3, p. 697-706, 2014.

LADWIG, Nilzo Ivo et al. Mapeamento da vulnerabilidade à inundação e ao deslizamento na bacia hidrográfica do Rio Urussanga, utilizando o método de análise hierárquica - AHP. In: LADWIG, Nilzo Ivo; SCHWALM, Hugo (Orgs.). Planejamento e gestão territorial: gestão integrada do território. Criciúma: UNESC, 2017. p.142-160.

NORONHA, G. C., et al. Análise do Índice de Anomalia de Chuva para a Microbacia de Santa Maria/Cambiocó, RJ. Revista Brasileira de Meteorologia, v. 31, n.1, p. 74-81, 2016.

ROOY, M. P.; VAN. A. Rainfall Anomaly Index Independent of Time and Space, Notes, v. 14, p. 1- 43, 1965.

SANCHES, F. O.; VERDUM, R.; FISCH, G. O índice de anomalia de chuva (IAC) na avaliação das precipitações anuais em Alegrete/RS (1928-2009). Caminhos de Geografia, v. 15, n. 51, p. 73-84, 2014.

TUCCI, C. E. M.; PORTO, R. L. L.; BARROS, M. T. (Orgs.). Drenagem Urbana. Porto Alegre: UFRGS e EDUSP ABRH, 2010.

TUNDISI, J. G. Recursos hídricos no futuro: problemas e soluções. Estudos Avançados, São Paulo, v. 22, n. 63, p. 7-16, 2008. 